\title{
Overuse of methylphenidate: an analysis of Swedish pharmacy dispensing data
}

This article was published in the following Dove Press journal:

Clinical Epidemiology

\author{
Pernilla J Bjerkeli ${ }^{1,2}$ \\ Raquel Perez Vicente ${ }^{2}$ \\ Shai Mulinari ${ }^{3}$ \\ Kristina Johnell ${ }^{4}$ \\ Juan Merlo 2,5
}

'Department for Biomedicine and Public Health Research, School of Health and Education, University of Skövde, Skövde, Sweden; ${ }^{2}$ Department of Clinical Sciences, Unit for Social Epidemiology, Faculty of Medicine, Lund University, Malmö, Sweden; ${ }^{3}$ Department of Sociology, Lund University, Lund, Sweden; ${ }^{4}$ Aging Research Center, Department of Neurobiology, Care Sciences and Society, Karolinska Institutet and Stockholm University, Stockholm, Sweden; ${ }^{5}$ Center for Primary Health Care Research, Region Skåne, Malmö, Sweden
Correspondence: Pernilla J Bjerkeli School of Health and Education, University of Skövde, Box 408, SE 54I 28 Skövde, Sweden

Tel +46500448405

Email pernilla.bjerkeli@his.se
Purpose: To identify overuse of methylphenidate and to investigate patterns of overuse in relation to sociodemographic and clinical characteristics.

Patients and methods: Swedish national, pharmacy dispensing data were analyzed for all 56,922 individuals aged 6-79 years, who filled a methylphenidate prescription between 2010 and 2011. Overuse was defined as having above $150 \%$ days covered by the dispensed amount during 365 days from the first prescription fill, assuming use at the maximum recommended daily dose. Results: In total, 4,304 individuals ( $7.6 \%$ of the methylphenidate users) were categorized as overusers. The risk of overuse increased with age (OR for 46-65 years vs 6-12 years 17.5, 95\% CI 14.3-21.3), and was higher in men (OR 1.4, 95\% CI 1.3-1.5) and individuals with low income (OR 1.1, 95\% CI 1.0-1.2), as well as in individuals with an attention deficit hyperactivity disorder (ADHD) diagnosis (OR 1.4, 95\% CI 1.3-1.6), health care visits (OR 1.3, 95\% CI 1.2-1.4), previous ADHD medication use (OR 2.6, 95\% CI 2.4-2.8), and previous diagnosis of mental and behavioral disorders due to psychoactive substance use (OR 2.1 95\% CI 2.0-2.3). Conclusion: Among individuals using methylphenidate in Sweden, 7.6\% receive amounts that are larger than what they should have a medical need for, assuming that they were using the maximum recommended daily dose 365 days per year. Notably, the prevalence of overuse was associated with previous diagnosis of alcohol and drug misuse. The prevalence was also positively associated with higher age and previous use of ADHD medication. These findings may point toward a link between exposure time and overuse. However, future studies with long-term data are needed to investigate this.

Keywords: methylphenidate, prescription drug diversion, pharmacoepidemiology, attention deficit disorder with hyperactivity, prescription drug overuse

\section{Introduction}

Methylphenidate is the first-line pharmacological treatment for attention deficit hyperactivity disorder (ADHD) in Sweden and other countries. ${ }^{1-3}$ The evidence base for this treatment is, however, debated. ${ }^{4-6}$ Two Cochrane meta-analyses have concluded that the evidence supporting safety ${ }^{5}$ and effect $^{6}$ for treatment of children and adolescents with ADHD is low, whereas another recent meta-analysis has found support for use of methylphenidate in children and adolescents with ADHD, at least in the available evidence for short-term treatment. ${ }^{4}$

The use of ADHD medication is increasing in several countries. ${ }^{7-9}$ Public data from the Swedish National Board of Health and Welfare - the national authority for social and health services - show that between 2006 and 2016, the prevalence of methylphenidate 
use in Sweden increased from 1.6 to 8.9 per 1,000 inhabitants aged 5-79 years. ${ }^{10}$ The use of methylphenidate in the population has been studied in some detail in Sweden ${ }^{8,11-14}$ and elsewhere, ${ }^{15-17}$ and studies show that the prevalence of use is higher among children than adults and among men than women. ${ }^{8,12}$ Studies from Sweden and the UK indicate that socioeconomic disadvantage is associated with use of ADHD medication, ${ }^{14,16}$ whereas the opposite association has been observed in studies from the US and Israel. ${ }^{15,17}$

Methylphenidate is classified as a narcotic drug..$^{18}$ Several studies have shown that it is indeed subject to overuse. ${ }^{19-27}$ Studies among college students and other adolescents in the US indicate that illicit use increased between 2003 and 2013, and that it was more common among boys than girls..$^{24,25}$ The most commonly reported reason for misuse is cognitive enhancement. ${ }^{27}$ The Swedish National Board of Health and Welfare recently published a report concluding that a majority of the methylphenidate confiscated by Swedish police was originally sold in Sweden via the regular pharmaceutical distribution chain. ${ }^{28}$ Indeed, it is highly likely that a proportion of the methylphenidate prescribed through the regular health care system is subject to illicit exchange and overuse, so-called drug diversion. ${ }^{23}$ Individuals who receive large amounts of the medication by prescription may overuse it themselves or distribute it to others. Still, rather little is known about the extent and epidemiology of this kind of overuse. In this study, we used Swedish national, pharmacy dispensing data with detailed information on the amounts of drug dispensed to identify overuse of methylphenidate. In addition, we have investigated patterns of overuse in relation to sociodemographic and clinical characteristics.

\section{Patients and methods}

\section{Context}

In Sweden, methylphenidate has been approved for treatment of ADHD in children and adolescents since $2002 .{ }^{29}$ In 2010, continued use among adults who had initiated the treatment as children or adolescents was approved, and in 2014, the indication was further broadened to include new treatment of adults with ADHD. ${ }^{30}$ Although not formally approved in Sweden, methylphenidate is also recommended for treatment of narcolepsy. ${ }^{31}$ Off-label use has also been reported for depression and Parkinson's disease. ${ }^{32}$ In Sweden, only physicians with a specialization in psychiatry may prescribe methylphenidate. ${ }^{29}$ Methylphenidate is included in the Swedish pharmaceutical reimbursement scheme, which means that the users only pay a limited proportion of the cost.

\section{Registers}

All data were retrieved from national registers. Information about pharmacy dispensing was retrieved from the Swedish Prescribed Drug Register (SPDR). ${ }^{33}$ The SPDR is administrated by the National Board of Health and Welfare and records information on all drug dispensations made at Swedish pharmacies, thus excluding those used in hospitals or from nursing home store rooms. For each dispensation, information is recorded, including the date of dispensation, the Anatomical Therapeutic Chemical code of the dispensed medication, the number of defined daily doses, and the prescribed amount. Using the Swedish unique personal identification number, the SPDR was linked to the Swedish Patient Register, ${ }^{34}$ which records all inpatient and outpatient diagnoses from hospitals in Sweden, using the ICD-10 codes. ${ }^{35}$ Finally, the research database was merged with the LISA register (http://www.scb.se/lisa), which is administrated by Statistics Sweden and combines information from several other registers with data on demographic and socioeconomic factors as well as on living conditions. The record linkage was performed by the Swedish authorities after approval by both their data safety committee and the Ethical Committee at Lund University (Reference No. 2014/856). Data were delivered to us after anonymization.

\section{Study sample}

Using the SPDR, we identified all 58,508 users and their 681,202 dispensations of methylphenidate (Anatomical Therapeutic Chemical code N06BA04) between January 1, 2010 and December 31, 2011. Thereafter, we selected the 56,922 individuals aged 6-79 years who were continuously residing in Sweden between January 1, 2005 and December 31,2012 to ensure availability and accuracy of the demographic, socioeconomic, and clinical variables. The final sample thus included 56,922 individuals and their 453,978 dispensations of methylphenidate.

\section{Assessment of variables}

\section{Overuse of methylphenidate}

We identified the indicated maximum doses for each pharmaceutical specialty included in our data. All Concerta ${ }^{\circledR}$ specialties had a maximum recommended dose of $54 \mathrm{mg} /$ day. ${ }^{36}$ This value was $60 \mathrm{mg} /$ day for Equasym Depot ${ }^{\circledR}$ in any form ${ }^{37}$ and $80 \mathrm{mg} / \mathrm{day}(60 \mathrm{mg} /$ day for children) for Ritalin $^{\circledR 38}$ and Medikinet ${ }^{\circledR 39}$ in any form. The total amount of methylphenidate dispensed to an individual during 365 days from the date of the first prescription fill of methylphenidate 
from 2010 to 2011 (the inclusion date) was divided by the maximum daily dose, yielding the "days of coverage." Days of coverage thus represents the number of days covered by the dispensed amount of methylphenidate, assuming that the patient was using the maximum recommended daily dose. Finally, we calculated the "percentage of the year covered" (coverage) by dividing "days of coverage" by 365 days and multiplying by 100 . Overuse was defined as having a coverage of above $150 \%$. However, prevalence figures for above $120 \%$ and above $200 \%$ coverage are also presented.

\section{Independent variables}

The independent variables were assessed as follows:

Individualized disposable household income: the total disposable income of a family in 2010 divided by the number of family members (weighted differently depending on age). Lower income was defined as the first tertile group and higher income as the second and third tertile groups.

ADHD diagnosis: a registered ADHD diagnosis (ICD10 code F90) during the study period or in the previous 5 years (yes/no).

Diagnosis of mental and behavioral disorders due to psychoactive substance use (ICD-10 codes F10-F19) and diagnosis of narcolepsy (ICD-10 code G47.4): registered diagnosis in the 5 years before the inclusion date (yes/no).

Previous use of ADHD medication: at least one prescription fill of amphetamine (N06BA01), dexamphetamine (N06BA02), methylphenidate (N06BA04), or atomoxetine (N06BA09) in the 5 years before the inclusion date (yes/no).

Specialist health care visit: visit to any clinic within psychiatry, neurology, specialist health care for children or adolescents, or care for drug addiction according to the Swedish codes for medical activities (MVO codes 24, 201, 202, 221, 251, 331, 401, 551, 552, 553, 572, 901, 928, 931, $943,944,953,954,956,957)$ registered during the study period (yes/no).

Any health care visit: visit to any in- or outpatient care facility in Sweden during the study period (yes/no).

\section{Statistical analysis}

We compared the population overusing methylphenidate to the population of methylphenidate users who were not overusers. We developed bivariate and multiple logistic regression models to obtain ORs and 95\% CIs of the associations between overuse of methylphenidate and a number of independent variables. Four consecutive regression models were applied. Model 1 contained only age; Model 2 included age, sex, and household income; Model 3 included age and clinical variables (ADHD diagnosis, health care visit, previous use of ADHD medication, and previous diagnosis of mental and behavioral disorders due to psychoactive substance use); and Model 4 contained age, sex, household income, and the clinical variables.

The discriminatory accuracy (DA) of the regression models was analyzed using the area under the receiver operating characteristic curve (AUC). This provided a measure of the models' ability to discriminate between those overusing and not overusing methylphenidate. The AUC takes a value between 1 and 0.5 , where 1 is perfect discrimination and 0.5 indicates that the independent variables have no predictive power.

An additional analysis was performed to provide more detail on different levels of overuse. Instead of dichotomously categorizing overuse as in the previous analyses, we used the following categories representing different levels of overuse: $101 \%-120 \%$ coverage, $121 \%-150 \%$ coverage, $151 \%-200 \%$ coverage, and $>200 \%$ coverage. We described those categories in relation to the independent variables included in Model 4.

Data management was performed with STATA, and all statistical analyses were performed with IBM SPSS 22.0.

\section{Results}

The study sample included 56,922 individuals aged 6-79 years, who had filled at least one prescription of methylphenidate in Sweden between 2010 and 2011. Among these, 4,304 (7.6\%) filled prescriptions representing above $150 \%$ coverage. These were categorized as overusers (Table 1).

\section{Bivariate logistic regression}

The prevalence of overuse increased with increasing age until the age of 65 years, being $1 \%(n=120)$ among children aged 6-12 years and $18.5 \%(n=890)$ among $46-65$ year olds (Table 1). In the study population, $22.3 \%(n=12,678)$ received a prescription of methylphenidate without having a diagnosis of ADHD registered during the study period or the previous 5 years. Not everyone had made a health care visit during the study period. A total of $32.0 \%(n=18,238)$ did not visit a clinic likely to work with ADHD (as defined in the "Materials and methods" section), and 18.6\% $(\mathrm{n}=10,613)$ had not visited any in- or outpatient care facility during the study period (Table 1). Overuse was more common among those who had a registered ADHD diagnosis than among those who did not (8.4\% vs 4.6\%, OR 1.92, 95\% CI 1.75-2.10) and among those who had a health care visit during the study 
Table I Prevalence of methylphenidate overuse (defined as having filled prescriptions during I year representing above I50\% drug coverage) among individuals aged 6-79 years, residing in Sweden, and using methylphenidate

\begin{tabular}{|c|c|c|c|c|c|c|}
\hline & \multirow{3}{*}{$\begin{array}{l}\text { Users } \\
n \\
\end{array}$} & \multicolumn{5}{|c|}{ Overusers } \\
\hline & & \multirow[t]{2}{*}{$\mathbf{n}$} & \multirow{2}{*}{$\begin{array}{l}\text { Prevalence } \\
\% \\
\end{array}$} & \multirow[t]{2}{*}{ OR } & \multicolumn{2}{|l|}{$95 \% \mathrm{Cl}$} \\
\hline & & & & & Lower & Upper \\
\hline Total & 56,922 & 4,304 & 7.56 & - & & \\
\hline \multicolumn{7}{|c|}{ Age (years) } \\
\hline $6-12$ & 11,999 & 120 & 1.00 & $\mathrm{I} .00$ (ref.) & & \\
\hline $13-18$ & 17,588 & 652 & 3.71 & 3.81 & 3.13 & 4.64 \\
\hline $19-29$ & 12,183 & 916 & 7.52 & 8.05 & 6.64 & 9.75 \\
\hline $30-45$ & 10,350 & $\mathrm{I}, 726$ & 16.68 & 19.81 & 16.43 & 23.89 \\
\hline $46-65$ & 4,627 & 873 & 18.87 & 23.02 & 18.95 & 27.96 \\
\hline 66-79 & 175 & 17 & 9.71 & 10.65 & 6.26 & 18.13 \\
\hline \multicolumn{7}{|l|}{ Sex } \\
\hline Women & 20,679 & 1,479 & 7.15 & $\mathrm{I} .00$ (ref.) & & \\
\hline Men & 36,243 & 2,825 & 7.79 & 1.10 & 1.03 & 1.17 \\
\hline \multicolumn{7}{|c|}{ Household income } \\
\hline Higher & 24,770 & 1,810 & 7.31 & $\mathrm{I} .00$ (ref.) & & \\
\hline Lower & 32,152 & 2,494 & 7.76 & 1.07 & 1.00 & 1.14 \\
\hline \multicolumn{7}{|c|}{ ADHD diagnosis } \\
\hline No & 12,678 & 580 & 4.57 & $\mathrm{I} .00$ (ref.) & & \\
\hline Yes & 44,244 & 3,724 & 8.42 & 1.92 & 1.75 & 2.10 \\
\hline \multicolumn{7}{|c|}{ Specialist health care visit } \\
\hline No & 18,238 & 1,265 & 6.94 & $\mathrm{I} .00$ (ref.) & & \\
\hline Yes & 38,684 & 3,039 & 7.86 & 1.14 & 1.07 & 1.22 \\
\hline \multicolumn{7}{|c|}{ Health care visit } \\
\hline No & 10,613 & 532 & 5.01 & $\mathrm{I} .00$ (ref.) & & \\
\hline Yes & 46,309 & 3,772 & 8.15 & 1.68 & 1.53 & 1.84 \\
\hline \multicolumn{7}{|c|}{ Previous ADHD medication use } \\
\hline No & 27,293 & 1,143 & 4.19 & $\mathrm{I} .00$ (ref.) & & \\
\hline Yes & 29,629 & 3,161 & 10.67 & 2.73 & 2.55 & 2.93 \\
\hline \multicolumn{7}{|c|}{ Previous diagnosis of alcohol and drug misuse } \\
\hline No & 48,882 & 2,693 & 5.51 & $\mathrm{I} .00$ (ref.) & & \\
\hline Yes & 8,040 & 1,611 & 20.04 & 4.30 & 4.02 & 4.60 \\
\hline \multicolumn{7}{|c|}{ Narcolepsy diagnosis } \\
\hline No & 52,440 & 4,290 & 7.56 & $\mathrm{I} .00$ (ref.) & & \\
\hline Yes & 178 & 14 & 7.29 & 0.96 & 0.56 & 1.66 \\
\hline
\end{tabular}

Note: ORs and $95 \% \mathrm{Cls}$ are from bivariate logistic regression.

Abbreviations: ADHD, attention deficit hyperactive disorder; ref., reference.

period than among those who did not $(8.2 \%$ vs $5.0 \%$, OR $1.68,95 \%$ CI 1.53-1.854).

The prevalence of overuse was higher among individuals who had used ADHD medication before the study period than among those who were new users $(10.7 \%$ vs $4.2 \%$, OR $2.73,95 \%$ CI 2.55-2.93). The prevalence of overuse was also higher among individuals with previous diagnoses of mental and behavioral disorders due to psychoactive substance use than among those without ( $20.0 \%$ vs $5.5 \%$, OR $4.3,95 \% \mathrm{CI}$ 4.02-4.6), as shown in Table 1. A total of 192 individuals had a narcolepsy diagnosis (Table 1). In the group aged 6-12 years, there were 40 individuals with narcolepsy, and $1(n=1)$ of them was classified as an overuser.

\section{Multiple logistic regression analyses}

The conclusive association between overuse of methylphenidate and age (Model 1; Table 2) remained in subsequent multivariate models (Models 2-4). However, the association between overuse of methylphenidate and age was attenuated somewhat in Model 3, suggesting that the effect of age may partly be mediated through ADHD diagnosis, health care visit, previous ADHD medication use, and previous diagnosis of mental and behavioral disorders due to psychoactive substance use. In Model 4, which included all the independent variables listed in Table 2, overuse of methylphenidate was associated with age, sex, household income, ADHD diagnosis, health care visit, previous ADHD medication use, and 
Table 2 Associations between methylphenidate overuse (defined as having filled prescriptions during I year representing above I50\% of drug coverage) and age, sex, household income, ADHD diagnosis, health care visit, previous ADHD medication use, and diagnosis of mental and behavioral disorders due to psychoactive substance use in a population of individuals aged 6-79 years using methylphenidate and residing in Sweden

\begin{tabular}{|c|c|c|c|c|c|c|c|c|c|c|c|c|}
\hline & \multicolumn{3}{|l|}{ Model I } & \multicolumn{3}{|l|}{ Model 2} & \multicolumn{3}{|l|}{ Model 3} & \multicolumn{3}{|l|}{ Model 4} \\
\hline & \multirow[t]{2}{*}{ OR } & \multicolumn{2}{|l|}{$95 \% \mathrm{Cl}$} & \multirow[t]{2}{*}{ OR } & \multicolumn{2}{|l|}{$95 \% \mathrm{Cl}$} & \multirow[t]{2}{*}{ OR } & \multicolumn{2}{|l|}{$95 \% \mathrm{Cl}$} & \multirow[t]{2}{*}{ OR } & \multicolumn{2}{|l|}{$95 \% \mathrm{Cl}$} \\
\hline & & Lower & Upper & & Lower & Upper & & Lower & Upper & & Lower & Upper \\
\hline \multicolumn{13}{|c|}{ Age (years) } \\
\hline $6-12$ & $\mathrm{I} .00$ (ref.) & & & I.00 (ref.) & & & $\mathrm{I} .00$ (ref.) & & & I.00 (ref.) & & \\
\hline $13-18$ & 3.81 & 3.13 & 4.64 & 3.91 & 3.21 & 4.76 & 3.15 & 2.58 & 3.83 & 3.24 & 2.66 & 3.94 \\
\hline $19-29$ & 8.05 & 6.64 & 9.75 & 8.73 & 7.20 & 10.58 & 5.37 & 4.42 & 6.52 & 5.84 & 4.80 & 7.10 \\
\hline $30-45$ & 19.81 & 16.43 & 23.89 & 22.00 & 18.23 & 26.54 & 13.66 & 11.29 & $16.5 \mid$ & 15.04 & 12.42 & 18.21 \\
\hline $46-65$ & 23.02 & 18.95 & 27.96 & 25.98 & 21.37 & 31.58 & 15.73 & 12.90 & 19.17 & 17.46 & $|4.3|$ & 21.31 \\
\hline 66-79 & 10.65 & 6.26 & 18.13 & 12.73 & 7.46 & 21.70 & 9.12 & 5.31 & 15.67 & 10.39 & 6.03 & 17.88 \\
\hline \multicolumn{13}{|l|}{ Sex } \\
\hline Women & & & & $\mathrm{I} .00$ (ref.) & & & & & & I.00 (ref.) & & \\
\hline Men & & & & 1.55 & 1.45 & 1.66 & & & & $1.4 \mathrm{I}$ & 1.32 & 1.52 \\
\hline \multicolumn{13}{|c|}{ Household income } \\
\hline Higher & & & & 1.00 (ref.) & & & & & & $\mathrm{I} .00$ (ref.) & & \\
\hline Lower & & & & 1.19 & 1.11 & 1.27 & & & & 1.09 & 1.02 & 1.17 \\
\hline \multicolumn{13}{|c|}{ ADHD diagnosis } \\
\hline No & & & & & & & $\mathrm{I} .00$ (ref.) & & & $\mathrm{I} .00$ (ref.) & & \\
\hline Yes & & & & & & & 1.43 & 1.30 & 1.58 & 1.41 & 1.28 & 1.56 \\
\hline \multicolumn{13}{|c|}{ Health care visit } \\
\hline No & & & & & & & $\mathrm{I} .00$ (ref.) & & & I.00 (ref.) & & \\
\hline Yes & & & & & & & 1.25 & 1.13 & 1.38 & 1.29 & 1.16 & 1.43 \\
\hline \multicolumn{13}{|c|}{ Previous ADHD medication use } \\
\hline No & & & & & & & $\mathrm{I} .00$ (ref.) & & & 1.00 (ref.) & & \\
\hline Yes & & & & & & & 2.63 & 2.45 & 2.83 & 2.61 & 2.42 & 2.80 \\
\hline \multicolumn{13}{|c|}{ Previous diagnosis of alcohol and drug misuse } \\
\hline No & & & & & & & $\mathrm{I} .00$ (ref.) & & & $\mathrm{I} .00$ (ref.) & & \\
\hline Yes & & & & & & & 2.19 & 2.04 & 2.36 & 2.10 & 1.95 & 2.26 \\
\hline
\end{tabular}

Note: Values are ORs and $95 \% \mathrm{Cls}$ from logistic regression.

Abbreviations: ADHD, attention deficit hyperactivity disorder; ref., reference.

previous diagnosis of mental and behavioral disorders due to psychoactive substance use.

\section{Discriminatory accuracy}

As shown in Figure 1, most of the increase in DA was observed in Model 1 (AUC $=0.74,95 \%$ CI 0.73-0.75), which included only age. The sociodemographic variables in Model 2 (household income and sex) provided a $1.3 \%$ increase of the DA (0.74-0.75), and the contribution of the clinical variables in Model 3 was $5.4 \%(0.74-0.78)$. The AUC of the final model (Model 4) was 0.79 (95\% CI 0.78-0.80).

\section{Levels of overuse}

Finally, the study population was divided into five groups, depending on the amount of methylphenidate they had received during the study period (Table 3). High overuse ( $>200 \%$ coverage) was particularly common among indi- viduals aged 30-65 years and among individuals who had a previous diagnosis of mental and behavioral disorders due to psychoactive substance use.

\section{Discussion}

Our results show that methylphenidate is prescribed to certain individuals in amounts that are not in concordance with current guidelines..$^{1-3}$ Among individuals who filled prescriptions of methylphenidate, $7.6 \%$ filled prescriptions that represented above $150 \%$ of what they should need, assuming that the medication was prescribed according to maximum recommended dosage instructions. Similarly, 3.4\% filled prescriptions representing above $200 \%$ of what they should need. Among individuals with a previous diagnosis of mental and behavioral disorders due to psychoactive substance use, $11.3 \%$ had coverage of $200 \%$ or more. The prevalence of overuse increased with increasing age. 
Table 3 Prevalence of different levels of methylphenidate overuse (defined as having filled prescriptions during I year representing $121 \%-150 \%$, $151 \%-200 \%$, and $>200 \%$ drug coverage) among individuals aged 6-79 years residing in Sweden

\begin{tabular}{|c|c|c|c|c|c|c|c|c|c|c|}
\hline \multirow{2}{*}{$\begin{array}{l}\text { Percentage of time covered } \\
\text { with methylphenidate }\end{array}$} & \multicolumn{2}{|l|}{$<100 \%$} & \multicolumn{2}{|c|}{$101 \%-120 \%$} & \multicolumn{2}{|c|}{$121 \%-\mid 50 \%$} & \multicolumn{2}{|c|}{$151 \%-200 \%$} & \multicolumn{2}{|c|}{$>200 \%$} \\
\hline & $\mathbf{n}$ & $\%$ & $\mathbf{n}$ & $\%$ & $\mathbf{n}$ & $\%$ & $\mathbf{n}$ & $\%$ & $\mathbf{n}$ & $\%$ \\
\hline Total & 45,439 & 79.83 & 3,573 & 6.28 & 3,606 & 6.33 & 2,377 & 4.18 & 1,927 & 3.39 \\
\hline \multicolumn{11}{|l|}{ Age (years) } \\
\hline $6-12$ & 11,055 & 92.13 & 515 & 4.29 & 309 & 2.58 & 95 & 0.79 & 25 & 0.21 \\
\hline $13-18$ & 14,594 & 82.98 & $\mathrm{I}, 204$ & 6.85 & $\mathrm{I}, \mathrm{I} 38$ & 6.47 & 508 & 2.89 & 144 & 0.82 \\
\hline $19-29$ & 9,733 & 79.89 & 755 & 6.20 & 779 & 6.39 & 552 & 4.53 & 364 & 2.99 \\
\hline $30-45$ & 6,918 & 66.84 & 766 & 7.40 & 940 & 9.08 & 835 & 8.07 & 891 & 8.61 \\
\hline $46-65$ & 3,002 & 64,88 & 322 & 6.96 & 430 & 9.29 & 378 & 8.17 & 495 & 10.70 \\
\hline $66-79$ & 137 & 78,29 & 11 & 6.29 & 10 & 5.71 & 9 & 5.14 & 8 & 4.57 \\
\hline \multicolumn{11}{|l|}{ Sex } \\
\hline Women & 16,650 & 80.52 & $\mathrm{I}, 304$ & 6.31 & 1,246 & 6.03 & 860 & 4.16 & 619 & 2.99 \\
\hline Men & 28,789 & 79.43 & 2,269 & 6.26 & 2,360 & 6.51 & $\mathrm{I}, 5 \mathrm{I}$ & 4.19 & $\mathrm{I}, 308$ & 3.61 \\
\hline \multicolumn{11}{|l|}{ Household income } \\
\hline Higher & 19,865 & 80.20 & $\mathrm{I}, 524$ & 6.15 & $1,57 \mid$ & 6.34 & 999 & 4.03 & 811 & 3.27 \\
\hline Lower & 25,574 & 79.54 & 2,049 & 6.37 & 2,035 & 6.33 & $\mathrm{I}, 378$ & 4.29 & 1,116 & 3.47 \\
\hline \multicolumn{11}{|l|}{ ADHD diagnosis } \\
\hline No & 10,795 & 85.15 & 666 & 5.25 & 637 & 5.02 & 340 & 2.68 & 240 & 1.89 \\
\hline Yes & 34,644 & 78.30 & 2,907 & 6.57 & 2,969 & 6.71 & 2,037 & 4.60 & 1,687 & 3.81 \\
\hline \multicolumn{11}{|l|}{ Health care visit } \\
\hline No & 8,860 & 83.48 & 597 & 5.63 & 624 & 5.88 & 321 & 3.02 & 211 & 1.99 \\
\hline Yes & 36,579 & 78.99 & 2,976 & 6.43 & 2,982 & 6.44 & 2,056 & 4.44 & 1,716 & 3.71 \\
\hline \multicolumn{11}{|l|}{ Previous ADHD medication use } \\
\hline No & 23,923 & 80.74 & 1,238 & 4.54 & 989 & 3.62 & 680 & 2.49 & 463 & 1.70 \\
\hline Yes & 21,516 & 78.83 & 2,335 & 7.88 & 2,617 & 8.83 & $\mathrm{I}, 697$ & 5.73 & $\mathrm{I}, 464$ & 4.94 \\
\hline \multicolumn{11}{|c|}{ Previous diagnosis of alcohol and drug misuse } \\
\hline No & 40,267 & 82.38 & 2,989 & 6.11 & 2,933 & 6.00 & 1,675 & 3.43 & 1,018 & 2.08 \\
\hline Yes & 5,172 & 64.33 & 584 & 7.26 & 673 & 8.37 & 702 & 8.73 & 909 & 11.31 \\
\hline
\end{tabular}

Abbreviation: ADHD, attention deficit hyperactive disorder.

The strong association between age and overuse remained after controlling for sociodemographic as well as clinical variables. The importance of age was also underscored by the fact that a large proportion of the DA of all the regression models was provided by the age variable. Although the prevalence of overuse was substantially lower among children than among adults, it is notable that 120 children aged 6-12 years received methylphenidate, representing coverage above $150 \%$. These figures could not be explained by potential offlabel use for narcolepsy, as only one of the children receiving more methylphenidate than recommended had a registered narcolepsy diagnosis.

The overuse prevalence increased with increasing age until the age of 65, after which it decreased. This is in line with a recent large French study, based on the French General Health Insurance database, in which the mean dose and the frequency of pharmacy dispensing were highest in the group aged 25-49 years. ${ }^{26}$ A possible reason behind the positive association could be that older individuals are likely to have used the medication for a longer time than younger ones. Longer exposure to the medication may increase the risk for tolerance and thus lead to subsequent need for elevated doses. Indeed, a Danish study in which methylphenidate users were studied between 2003 and 2010 showed that the average dose of methylphenidate used by both children and adults increased with time. ${ }^{40}$ The fact that overuse was associated with previous use of ADHD medication in our study also points toward the suggestion that long exposure to methylphenidate may be linked to overuse. However, it should be noted that methylphenidate has only been approved for marketing in Sweden since 2002 (ie, 8 years before data collection was done for this study). In addition, prescribing of methylphenidate to adults was not approved until 2010. It is, however, known that off-label prescribing to adults took place before the extension of the approval, ${ }^{32}$ thus explaining why many adults are found among the users in this study and even among those who had previous use before the study period. Future research should investigate whether duration of methylphenidate use is a risk factor for overuse. Another possible factor behind the overrepresentation of overuse in higher age groups could be that, since the overall prevalence of methylphenidate use is lower in older age groups, ${ }^{8,12}$ those using methylphenidate in these age strata might represent a selection of individuals with more severe symptoms and 


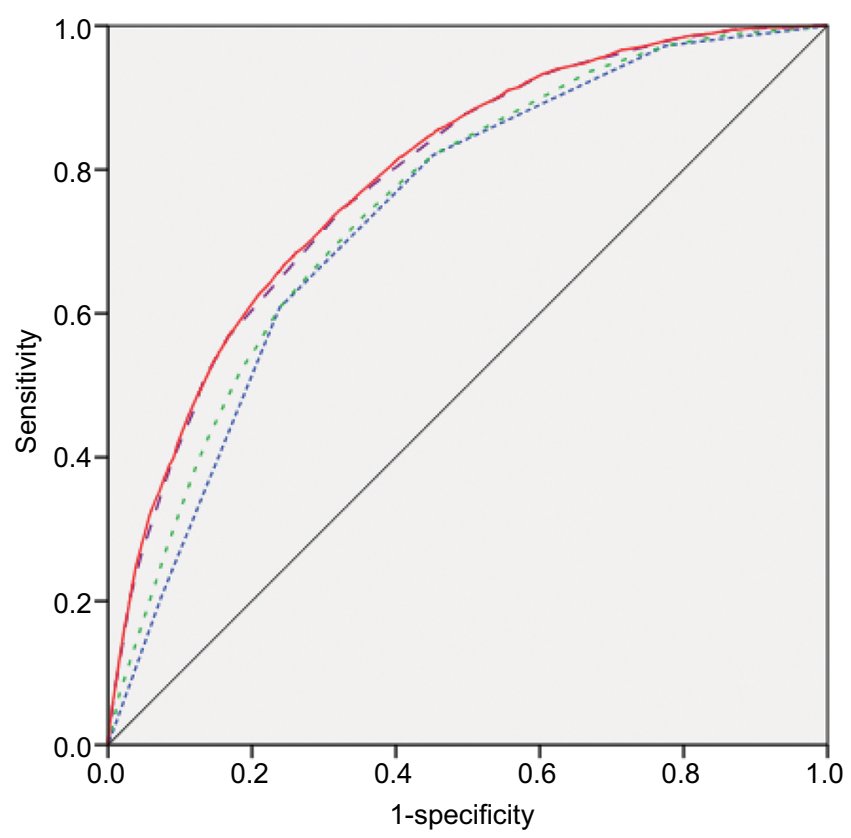

\begin{tabular}{|l|l|l|l|l|}
\hline Models & Explanatory variables included & AUC & \multicolumn{2}{|c|}{$\mathbf{9 5 \%}$ CI } \\
\cline { 3 - 5 } & & & Lower & Upper \\
\hline Model I (blue dotted line) & Age & 0.74 & 0.73 & 0.75 \\
Model 2 (green dashed line) & Age, sex, income & 0.75 & 0.75 & 0.76 \\
Model 3 (purple dashed line) & Age, clinical variables & 0.79 & 0.78 & 0.79 \\
Model 4 (red solid line) & Age, sex, income, clinical variables & 0.79 & 0.78 & 0.80 \\
\hline
\end{tabular}

Figure I AUCs for methylphenidate overuse (defined as having filled prescriptions during I year representing above I50\% drug coverage) in a population of individuals aged 6-79 years using methylphenidate and residing in Sweden.

Notes: Black solid line represents AUC 0.5. Clinical variables are ADHD diagnosis, health care visit, previous ADHD medication use, and diagnosis of mental and behavioral disorders due to psychoactive substance use.

Abbreviations: ADHD, attention deficit hyperactive disorder; AUC, area under the receiver operating characteristic curve.

a higher need for treatment than the average patient. However, this does not explain why they received doses above recommended maximum doses. Another factor that could potentially contribute to the overrepresentation of overuse in higher age is that medication use in children and adolescents is usually managed by parents, whereas adults are usually responsible for their own medication use.

It is particularly notable that overuse, and especially high overuse, was more common among individuals who had a diagnosis of behavioral disorders due to psychoactive substance use. As more careful prescribing of psychostimulants to patients with such problems is expected, this could be regarded as a sign of irresponsible prescribing and illicit use. Not everyone had a health care visit registered during the year after their prescription fill of methylphenidate. This is not in line with treatment guidelines which recommend annual follow-ups with a specialist. ${ }^{1}$ Although lack of followup would intuitively be expected as a risk factor for overuse, the results do not confirm this. Individuals who did not have follow-up visits had a slightly lower prevalence of overuse. A possible explanation may be that they had less severe ADHD and thus used less medication. Another possible explanation is that individuals who were overusing had more health care visits because they were being more closely monitored by the health care provider.

\section{Strengths and weaknesses}

The study is based on national register data, which include individual-level information about all dispensations of methylphenidate made at Swedish pharmacies during the study period. The data also include information on sociodemographic and clinical variables covering all individuals in the study population. However, as with all analyses of pharmacy dispensing data, we do not have information about what the individuals do with the medication once they have collected it from the pharmacy. Hence, we do not know if the identified overuse represents overuse by the individual patient or whether the medications are being given or sold to someone else. This is a limitation. Also, the data do not provide information about illegal distribution of methylphenidate. 
It should be noted that the coverage of dispensed methylphenidate was calculated based on the assumption that all individuals were using the maximum recommended daily dose of methylphenidate, although clinical guidelines state that methylphenidate should be titrated to find the lowest effective dose for each individual. This may have led to an underestimation of the overuse prevalence. The cutoff for what is considered to be overuse was set at $150 \%$ coverage, although, in fact, anyone who had $>100 \%$ coverage at the maximum recommended daily dose could be defined as an overuser. We did, however, choose a more conservative definition to account for variations caused by the fact that some individuals may have made a prescription fill just before the cut-off of the study period, whereas others could have made their next prescription fill just after.

\section{Conclusion}

We found that $7.6 \%$ of individuals using methylphenidate in Sweden receive amounts that are larger than what they should have a medical need for, assuming that they were using the maximum recommended daily dose 365 days per year. Notably, the prevalence of overuse was associated with previous diagnosis of alcohol and drug misuse. The prevalence was also positively associated with higher age and previous use of ADHD medication. These findings may point toward a link between exposure time and overuse. However, future studies with long-term data are needed to investigate this.

\section{Ethical approval and informed consent}

The database was created by the Swedish National Board of Health and Welfare and Statistics Sweden after approval by both their data safety committees and the Regional Ethical Review Board at Lund University (Reference No. 2014/856). Informed consent was not obtained.

\section{Data sharing statement}

All data are available in national Swedish registers held by Statistics Sweden (http://www.scb.se/en /) and the National Board of Health and Welfare (http://www.socialstyrelsen.se/ english). The data are not public, but can be retrieved after ethical approval from a Regional Ethical Review Board in Sweden.

\section{Acknowledgments}

This study was supported by grants from the Swedish Research Council (VR) (2013-2484 and 2017-01321 to Juan Merlo). The authors advise no financial relationships with any organizations that might have an interest in the submitted work in the previous 3 years, and no other relationships or activities that could appear to have influenced the submitted work.

\section{Disclosure}

The authors report no conflicts of interest with this work.

\section{References}

1. Swedish Medical Products Agency. Läkemedel vid adhd - behandlingsrekommendation; 2016. [Medications in ADHD - treatment recommendation; 2016]. Available from: https://lakemedelsverket.se/upload/ halso-och-sjukvard/behandlingsrekommendationer/Lakemedel_\%20 vid_adhd_behandlingsrekommendation.pdf. Accessed April 16, 2018. Swedish.

2. Kendall T, Taylor E, Perez A, Taylor C; Guideline Development Group. Diagnosis and management of attention-deficit/hyperactivity disorder in children, young people, and adults: summary of NICE guidance. $B M J$. 2008;337:a1239.

3. Subcommittee on Attention-Deficit/Hyperactivity Disorder, Steering Committee on Quality Improvement and Management; Wolraich M. ADHD: clinical practice guideline for the diagnosis, evaluation, and treatment of attention-deficit/hyperactivity disorder in children and adolescents. Pediatrics. 2011;128(5):1007-1022.

4. Cortese S, Adamo N, del Giovane C, et al. Comparative efficacy and tolerability of medications for attention-deficit hyperactivity disorder in children, adolescents, and adults: a systematic review and network meta-analysis. Lancet Psychiatry. 2018;5(9):727-738.

5. Storebø OJ, Pedersen N, Ramstad E, et al. Methylphenidate for attention deficit hyperactivity disorder (ADHD) in children and adolescents - assessment of adverse events in non-randomised studies. Cochrane Database Syst Rev. 2018;5(5):CD012069.

6. Storebø OJ, Ramstad E, Krogh HB, et al. Methylphenidate for children and adolescents with attention deficit hyperactivity disorder (ADHD). Cochrane Database Syst Rev. 2015 (11):Cd009885.

7. Bachmann CJ, Wijlaars LP, Kalverdijk LJ, et al. Trends in ADHD medication use in children and adolescents in five western countries, 2005-2012. Eur Neuropsychopharmacol. 2017;27(5):484-493.

8. Zetterqvist J, Asherson P, Halldner L, Långström N, Larsson H. Stimulant and non-stimulant attention deficit/hyperactivity disorder drug use: total population study of trends and discontinuation patterns 2006-2009. Acta Psychiatr Scand. 2013;128(1):70-77.

9. Karanges EA, Stephenson CP, Mcgregor IS. Longitudinal trends in the dispensing of psychotropic medications in Australia from 2009-2012: focus on children, adolescents and prescriber specialty. Aust $N Z J$ Psychiatry. 2014;48(10):917-931.

10. Swedish Board of Health and Welfare. Statistikdatabasen. [The statistics database]. 2018. Available from: http://www.socialstyrelsen.se/statistik/ statistikdatabas/lakemedel. Accessed January 17, 2018. Swedish.

11. Bahmanyar S, Sundström A, Kaijser M, von Knorring AL, Kieler H. Pharmacological treatment and demographic characteristics of pediatric patients with Attention Deficit Hyperactivity Disorder, Sweden. Eur Neuropsychopharmacol. 2013;23(12):1732-1738.

12. Giacobini M, Medin E, Ahnemark E, Russo LJ, Carlqvist P. Prevalence, patient characteristics, and pharmacological treatment of children, adolescents, and adults diagnosed with ADHD in Sweden. JAtten Disord. 2018;22(1):3-13.

13. Chen Q, Sjölander A, Runeson B, D'Onofrio BM, Lichtenstein P, Larsson $\mathrm{H}$. Drug treatment for attention-deficit/hyperactivity disorder and suicidal behaviour: register based study. BMJ. 2014;348:g3769.

14. Jablonska B, Kosidou K, Ponce de Leon A, et al. Neighborhood socioeconomic characteristics and utilization of ADHD medication in schoolchildren: a population multilevel study in Stockholm County. J Atten Disord. 2016. 
15. Bokhari F, Mayes R, Scheffler RM. An analysis of the significant variation in psychostimulant use across the U.S. Pharmacoepidemiol Drug Saf. 2005;14(4):267-275.

16. Miller AR, Lalonde CE, Mcgrail KM, Armstrong RW. Prescription of methylphenidate to children and youth, 1990-1996. CMAJ. 2001;165(11):1489-1494.

17. Jaber L, Rigler S, Shuper A, Diamond G. Changing epidemiology of methylphenidate prescriptions in the community: a multifactorial model. J Atten Disord. 2017;21(14):1143-1150.

18. United Nations. Convention on Psychotropic Substances. Vienna; 1971.

19. Clemow DB. Misuse of Methylphenidate. Curr Top Behav Neurosci. 2017;34:99-124.

20. Wilens TE, Adler LA, Adams J, et al. Misuse and diversion of stimulants prescribed for ADHD: a systematic review of the literature. J Am Acad Child Adolesc Psychiatry. 2008;47(1):21-31.

21. Bjarnadottir GD, Haraldsson HM, Rafnar BO, et al. Prevalent intravenous abuse of methylphenidate among treatment-seeking patients with substance abuse disorders: a descriptive population-based study. J Addict Med. 2015;9(3):188-194.

22. Frauger E, Amaslidou D, Spadari M, et al. Patterns of methylphenidate use and assessment of its abuse among the general population and individuals with drug dependence. Eur Addict Res. 2016;22(3):119-126.

23. Vrecko S. Everyday drug diversions: a qualitative study of the illicit exchange and non-medical use of prescription stimulants on a university campus. Soc Sci Med. 2015;131:297-304.

24. Teter CJ, Mccabe SE, Lagrange K, Cranford JA, Boyd CJ. Illicit use of specific prescription stimulants among college students: prevalence, motives, and routes of administration. Pharmacotherapy. 2006;26(10):1501-1510.

25. Mccabe SE, West BT, Teter CJ, Boyd CJ. Trends in medical use, diversion, and nonmedical use of prescription medications among college students from 2003 to 2013: connecting the dots. Addict Behav. 2014;39(7):1176-1182.

26. Pauly V, Frauger E, Lepelley M, Mallaret M, Boucherie Q, Micallef J. Patterns and profiles of methylphenidate use both in children and adults. Br J Clin Pharmacol. 2018;84(6):1215-1227.

27. Compton WM, Han B, Blanco C, Johnson K, Jones CM. Prevalence and correlates of prescription stimulant use, misuse, use disorders, and motivations for misuse among adults in the United States. Am J Psychiatry. 2018;175(8):741-755

28. Swedish Board of Health and Welfare. Felanvändning av metylfenidat: En undersökning om avledning och sidoförskrivning. [Misuse of methylphenidate: a study of diversion and lateral prescribing]. 2018. Available from: https://www.socialstyrelsen.se/Lists/Artikelkatalog/Attachments/20798/2018-1-2.pdf. Accessed February 12, 2018. Swedish.

29. Swedish Medical Products Agency. Läkemedelsverkets följer upp behandlingen med centralstimulantia vid ADHD; 2013. [The Swedish Medical Products Agency analyses stimulant ADHD medication treatment]. Available from: https://lakemedelsverket.se/Alla-nyheter/ Nyheter-2013/Lakemedelsverkets-foljer-upp-behandlingen-medcentralstimulantia-vid-ADHD/. Accessed April 18, 2018. Swedish.
30. Swedish Medical Products Agency. Information från Läkemedelsverket; 2014. [Information from the Swedish Medical Products Agency; 2014]. Available from: https://lakemedelsverket.se/upload/om-lakemedelsverket/publikationer/information-fran-lakemedelsverket/2014/ Information_fran_lakemedelsverket_nr_5_2014_webb.pdf. Accessed 5, 25. Swedish.

31. Swedish Medical Products Agency. Läkemedelsbehandling av narkolepsi - ett kunskapsdokument; 2013. [Drug treatment of narcolepsy - a knowledge document; 2013]. Available from: https://lakemedelsverket.se/upload/halso-och-sjukvard/behandlingsrekommendationer/ L\%C3\%A4kemedelsbehandling\%20vid\%20narkolepsi\%20-\%20 ett\%20kunskapsdokument.pdf. Accessed April 18, 2018. Swedish.

32. Trenque T, Herlem E, Abou Taam M, Drame M. Methylphenidate offlabel use and safety. Springerplus. 2014;3:286.

33. Wettermark B, Hammar N, Fored CM, et al. The new Swedish Prescribed Drug Register - opportunities for pharmacoepidemiological research and experience from the first six months. Pharmacoepidemiol Drug Saf. 2007;16(7):726-735.

34. Ludvigsson JF, Andersson E, Ekbom A, et al. External review and validation of the Swedish national inpatient register. BMC Public Health. 2011;11:450.

35. Socialstyrelsen S. Internationell statistisk klassifikation av sjukdomar och relaterade hälsoproblem: (ICD-10-SE). Systematisk förteckning. Svensk. [International Statistical Classification of Diseases and Related Health Problems (ICD-10-SE), Swedish Edition]. Stockholm: Socialstyrelsen; 2010. Swedish

36. Summary of Product Characteristics for Concerta. Available from: https:/www.fass.se/LIF/product?userType=0\&nplId=200211010003 35\&docType $=6 \&$ scrollPosition=516. Accessed August 15, 2018.

37. Summary of Product Characteristics for Equasym Depot. Available from: https://www.fass.se/LIF/product?userType=0\&nplId=200406 $07006450 \&$ doc Type $=6 \&$ scrollPosition $=380$. Accessed August 15, 2018.

38. Summary of Product Characteristics for Ritalin. Available from: https://www.fass.se/LIF/product?userType=0\&npIId=2008101000004 $8 \&$ doc Type $=6 \&$ scrollPosition $=638.4000244140625$. Accessed August $15,2018$.

39. Summary of Product Characteristics for Medikinet; 2018. Available from: https://www.fass.se/LIF/product?userType=0\&nplId=2010080 $4000054 \&$ docType $=6 \&$ scrollPosition $=704.7999877929688$. Accessed August 2015.

40. Pottegård A, Bjerregaard BK, Glintborg D, Kortegaard LS, Hallas J, Moreno SI. The use of medication against attention deficit/hyperactivity disorder in Denmark: a drug use study from a patient perspective. Eur J Clin Pharmacol. 2013;69(3):589-598.
Clinical Epidemiology

\section{Publish your work in this journal}

Clinical Epidemiology is an international, peer-reviewed, open access, online journal focusing on disease and drug epidemiology, identification of risk factors and screening procedures to develop optimal preventative initiatives and programs. Specific topics include: diagnosis, prognosis, treatment, screening, prevention, risk factor modification,

Submit your manuscript here: https://www.dovepress.com/clinical-epidemiology-journal systematic reviews, risk and safety of medical interventions, epidemiology and biostatistical methods, and evaluation of guidelines, translational medicine, health policies and economic evaluations. The manuscript management system is completely online and includes a very quick and fair peer-review system, which is all easy to use. 